\title{
EFEITO DA MATURAÇÃO DA CARNE NA QUALIDADE SANITÁRIA DO JERKED BEEF
}

\section{INFLUENCE OF MEAT MATURATION ON THE QUALITY OF JERKED BEEF}

\author{
Vanessa Kelly Capoia Vignoto ${ }^{1}$, Lígia Grisolia do Carmo ${ }^{2}$, \\ Sheila Rezler Wosiacki ${ }^{3}$
}

1 Aluna do Curso de Pós Graduação em Ciência e Tecnologia Agroindustrial e Técnica do Laboratório de Microbiologia Animal da UEM.

2 Aluna do Curso de Pós Graduação em Ciência e Tecnologia Agroindustrial e Técnica do Laboratório de Anatomia Animal e do Laboratório de Alimentos da UEM

3 Professora Doutora da Universidade Estadual de Maringá. Departamento de Medicina Veterinária. E-mail: <wosiacki@yahoo.com.br>

\section{RESUMO}

O Jerked Beef, um produto preservado pelo sal e elaborado principalmente a base de carne de origem bovina. Seu processo consiste normalmente, na salga úmida, salga seca, secagem ao sol, abafamento e embalagem à vácuo. Este trabalho avaliou a qualidade do processamento do Jerked beef pela contagem total de bactérias mesófilas, Staphylococcus spp, bolores e leveduras e pesquisa do número mais provável (NMP) de coliformes totais e fecais. Nas análises microbiológicas observou-se que a contagem total de microrganismos mesófilos variou desde $>5 \times 10^{4} \mathrm{UFC} / \mathrm{g}$ até o desaparecimento total após a salga e a secagem. A contagem para Staphylococcus spp foi desde $6 \times 10^{3} \mathrm{NMP} / \mathrm{g}$ até desaparecimento total após a salga e a secagem. A contagem de bolores e leveduras apresentou valores de 7,5×10 ${ }^{3} \mathrm{NMP} / \mathrm{g}$ até $1 \times 10^{3} \mathrm{NMP} / \mathrm{g}$. O número mais provável de coliformes totais variou de $30 \mathrm{NMP} / \mathrm{g}$ até $>24000 \mathrm{NMP} / \mathrm{g}$ após a salga e desapareceu após a secagem. Os microrganismos, em relação à carne, estão diretamente ligados ao processo de deterioração, infecção e intoxicação alimentar. Os resultados confirmam contaminação durante o processo do Jerkey beef, mas o uso de agentes de preservação e o tipo de processamento diminuiu de forma significativa esta contaminação sendo que os bolores e levaduras estavam presentes em quantidades aceitas pela legislação em vigor.

Palavras-chave: Jerked beef. Microrganismos. Carne. 


\begin{abstract}
Jerked beef is a salt preserved product produced mainly with beef. The process comprehends wet salting, dried salting, sun drying, smothering and vacuum packing. This work evaluated the sanitary-hygienic quality of Jerked beef processing by total counting of aerobic mesophila bacteria, Staphylococcus spp, mould and yeast and probable number of fecal as well as total coliform. Total counting of mesophylla microorganisms varied from $5 \times 10^{4} \mathrm{UFC} / \mathrm{g}$ in the beginning to total absence after salt addition and drying process. The count for Staphylococcus spp varied from $6 \times 10^{3} \mathrm{UFC} / \mathrm{g}$ in the beginning to total absence after salting and drying. The mould and yeast counting showed figures from $7.5 \times 10^{3} \mathrm{UFC} / \mathrm{g}$ to $1 \times 10^{3} \mathrm{UFC} / \mathrm{g}$ during the processing. The most probable number of total coliform goes from $30 \mathrm{NMP} / \mathrm{g}$ up to $24,000 \mathrm{NMP} / \mathrm{g}$ after salt addition but it disappeared after the drying process. The microorganims related to meat has a close relation to the deterioration, infection and food poisoning . The results confirm contamination during the Jerked beef processing, but the preservative addition and the kind of processing reduced significantly this contamination. Furthermore, mould and yeast were found in amounts accepted by the specific legislation.
\end{abstract}

Keywords: Jerked beef. Microorganims. Meat.

\section{INTRODUÇÃO}

Charque é um produto cárneo salgado e seco ao sol, típico do Brasil e outros países da América do Sul. Embora seja um dos produtos cárneos industrializados mais consumidos no país (SHIMOKOMAKI, 1987), seu potencial de comercialização está longe de ser completamente explorado, mesmo em nível nacional (FAYRDIN, 1991). A necessidade de ampliar o mercado consumidor fez com que as indústrias buscassem alternativas para melhorar a qualidade e a imagem do produto, Uma tentativa nesse sentido fez surgir o Jerked beef, produto que difere do charque em alguns pontos, sendo o principal a adição de sais de cura à matéria prima no início do processamento e a diminuição da quantidade de cloreto de sódio na salga, além de ser embalado a vácuo (PINTO et al., 1998).

O processo de salga altera a pressão osmótica da carne, o que faz com que a água seja removida dos tecidos, provocando redução da atividade de água, inibindo o desenvolvimento microbiano (COSTA; SILVA, 1999). As etapas para o processamento do Jerked beef consistem inicialmente da desossa, salga úmida, salga seca, tombo, lavagem, secagem ao sol e abafamento, embalagem e finalmente comercialização (SHIMOKOMAKI et al., 2003; LARA et al., 1999).

Sua obtenção requer uma série de etapas de manipulação, o que eleva as possibilidades de contaminação por muitas espécies de microrganismos, patogênicos ou deterioradores, e que pode comprometer a qualidade microbiológica do produto final (BORCH et al., 1996).

Durante o processo, ocorrem simultaneamente, dois fenômenos de transferência de massa em contra-fluxo. Ocorre difusão da umidade do interior da carne para o exterior e difusão de sal, entrando na carne, com conseqüente diminuição da umidade, aumento no teor de sal e redução da atividade de água (SABADINI et al., 2001).

Silva (2002) define os nitritos e nitratos como conservantes inorgânicos que inibem ou retardam a multiplicação dos microrganismos. PARDI et al. (1995) haviam relatado em suas pesquisas que o principal atributo do nitrito é garantir a estabilidade microbiológica das carnes curadas, inibindo o desenvolvimento de diversas bactérias patogênicas.

A maturação da carne consiste na manutenção da carne, após o processo de rigor mortis, sob refrigeração (temperatura em torno de $0^{\circ} \mathrm{C}$ ), por um 
período de tempo após o abate que pode variar de 7 a 21 dias. O objetivo da maturação é melhorar as características organolépticas do produto como maciez, sabor e suculência (PENNA; SCHETTINI, 1999). Em virtude de ser um alimento rico em elementos nutritivos, depois de uma permanência relativamente longa em temperaturas de refrigeração, pode ocorrer o crescimento de microrganismos (VASCONCELOS et al., 2002).

O processo de maturação envolvendo a embalagem a vácuo da carne, retarda o crescimento de bactérias aeróbicas putrefativas e favorece o crescimento das bactérias anaeróbias láticas, que por sua vez, produzem substâncias antimicrobianas (PUGA et al., 1999). Os alimentos de origem animal, especificamente a carne, pela sua composição rica em nutrientes e sua elevada atividade de água, são bastante susceptíveis à deterioração microbiana, sendo um excelente meio de cultura para o desenvolvimento de microrganismos patogênicos causadores de enfermidades ao homem e animais (OLIVEIRA et al, 2008; VASCONCELOS et. al., 2002).

A microbiota da carne depende das condições nas quais os animais foram criados, abatidos e processados (SILVA, 1997). Fatores intrínsecos e extrínsecos, como atividade de água, pH, composição química, temperatura e umidade podem alterar a microbiota natural da carne de origem bovina (TAVARES; SERAFINI, 2003). A contaminação pode ocorrer em todas as operações de abate, armazenamento e distribuição e sua intensidade depende da eficiência das medidas higiênicas adotadas (BORCH et al., 1996; COSTA E SILVA, 2001).

Um fator que pode ser determinante para as altas contagens de microrganismos encontradas no Jerked beef é o baixo teor de sal utilizado, suficiente apenas para reduzir a atividade de água mas oferecendo condições favoráveis para o desenvolvimento de bactérias Gram-positivas, como as pertencentes ao gênero Staphylococcus (SILVA, 1991).

A contagem total das bactérias mesófilas de um produto pode ser utilizada como indicativo do histórico da manipulação a que ele foi submetido, com reflexo na qualidade da matéria-prima empregada, bem como no tempo de prateleira do produto final (COSTA; SILVA, 2001).

A proposta deste artigo foi avaliar e quantificar os microrganismos que podem afetar a qualidade higiênico-sanitária durante o processamento do Jerked beef com carne, maturada ou não, de origem bovina.

\section{MATERIAIS E MÉTODOS}

\subsection{Processamento do Jerked beef}

O processamento do Jerked beef foi realizado no Laboratório de Alimentos da Universidade Estadual de Maringá - Campus Regional de Umuarama. Foram utilizadas carnes de quatro fêmeas de bovinos de cruzamento das raças Nelore e Red Angus, com idades média de 17 meses, abatidos em processamento industrial.

Foi coletado o músculo Vastus Lateralis, conhecido comercialmente como patinho. Os músculos foram cortados em camadas com 3 a $5 \mathrm{~cm}$ de espessura e estes foram divididas em partes iguais, chamadas de mantas $(19 \mathrm{~cm} \times 11 \mathrm{~cm})$. Foram utilizadas 24 mantas de carne, sendo 12 submetidas ao processo de maturação e 12 utilizadas in natura, congeladas durante o período de maturação.

A maturação foi realizada segundo a técnica descrita por (Penna, 1999), as mantas foram embaladas à vácuo e refrigeradas a $4^{\circ} \mathrm{C}$ por 6 dias e após este períodos de maturação as carnes oram desembaladas e as carnes não maturadas $a$ foram descongeladas, seguindo o processamento do Jerked beef. Para o processamento do Jerked beef foi utilizada a técnica descrita por (SHIMOKOMAKI et al., 2003). As mantas foram mergulhadas em uma salmoura contendo cerca de $25 \%$ de cloreto de sódio, nitrito de sódio e nitrato de sódio (Kraki) na proporção de $350 \mathrm{~g}$ para $100 \mathrm{~kg}$ de carne por 50 minutos, para a penetração e disseminação do sal. Após esta primeira salga, as mantas foram colocadas umas sobre as outras e recobertas, uma a uma, por sal grosso constituindo a denominada "pilha", permanecendo assim por 24 horas. A pilha foi invertida durante cinco dias, diariamente, conhecida pelo termo "tombo". Após a segunda etapa de salga, as mantas foram lavadas para retirada do excesso de sal superficial e expostas ao sol em varais por um dia. Foram então recolhidas, empilhadas e abafadas sob lonas durante 48 horas, para o desenvolvimento do sabor e odor característico, retornando aos 
varais para mais dois períodos de exposição ao sol e abafamento. Ao final, as peças foram embaladas à vácuo.

\subsection{Análises microbiológicas}

As análises microbiológicas foram realizadas no Laboratório de Microbiologia Animal da Universidade Estadual de Maringá - Campus Regional de Umuarama, seguindo as etapas do processamento do Jerked beef (Quadro 1).

Quadro 1 - Etapas do Processamento do Jerked beef submetidas às análises microbiológicas

\begin{tabular}{|c|c|}
\hline $\begin{array}{c}\text { Fase do processamento do } \\
\text { Jerked beef }\end{array}$ & $\begin{array}{c}\text { Etapa para análise } \\
\text { microbiológica }\end{array}$ \\
\hline Carne in natura & Análise I \\
\hline $\begin{array}{c}\text { Carne após maturação e } \\
\text { descongelamento }\end{array}$ & Análise III \\
\hline $\begin{array}{c}\text { Carne após salga úmida e } \\
\text { tombos }\end{array}$ & Análise IV \\
\hline Carne após secagem
\end{tabular}

Foi feita a contagem de bactérias aeróbias mesófilas, bolores e leveduras, Staphylococcus $\boldsymbol{s p p}$, coliformes totais e coliformes termotolerantes, conforme metodologia recomendada pela Portaria do Ministério da Agricultura, Pecuária e Abastecimento $\mathrm{n}^{\circ} 12$, de 17 de setembro de 2001 e descrita por (VANDERZANT; SPLITTSTOESSER, 1992). Foram pesadas assepticamente $25 \mathrm{~g}$ de cada amostra. As amostras foram trituradas e diluídas em $225 \mathrm{~mL}$ de solução de água peptonada (Biobrás) $0,1 \%$. A diluição obtida corresponde a diluição $10^{-1}$, a partir da qual foram obtidas as demais diluições decimais até $10^{-4}$.

As diluições $10^{-2}$ e $10^{-3}$ foram semeadas (inadequada) em superfície em PCA (Himedia), incubado a $37^{\circ} \mathrm{C} / 48 \mathrm{~h}$ para pesquisa de bactérias aeróbias mesófilas; em Ágar batata dextrose, incubado $25^{\circ} \mathrm{C} / 96 \mathrm{~h}$ para contagem de bolores e leveduras; em Baird Parker (Himedia), incubado $37^{\circ} \mathrm{C} / 48 \mathrm{~h}$ para a indentificação de Staphylococcus spp, as colônias típicas foram coradas pela técnica de gram e submetidas aos testes de catalase e coagulase (Newprov).

A identificação de coliformes foi realizada pela técnica dos tubos múltiplos em triplicata das diluições decimais de $10^{-2}$ até $10^{-4}$. A prova presuntiva foi realizada em tubos contendo caldo lactosado (Acumedia) com tubos de Duran invertidos (precisa:) e incubados a $37^{\circ} \mathrm{C} / 48 \mathrm{~h}$. As provas confirmatórias foram realizadas em caldo EC (Acumedia) e caldo Verde Brilhante (Acumedia), os tubos contendo o caldo EC foram incubados a $45,5^{\circ} \mathrm{C} / 48 \mathrm{~h}$, e os contendo o caldo Verde brilhante foram incubados a $37^{\circ} \mathrm{C} / 48$ horas.

Tabela 1 - Resultados das análises microbiológicas realizadas durante o processamento do Jerked beef com carne maturada e não maturada

\begin{tabular}{|c|c|c|c|c|c|c|}
\hline Análise & Fases do processo & $\begin{array}{l}\text { Mesófilas } \\
\text { (UFC/g) }\end{array}$ & $\begin{array}{c}\text { Staphylococcus spp } \\
\text { (UFC/g) }\end{array}$ & $\begin{array}{c}\text { Bolores e } \\
\text { leveduras } \\
\text { (UFC/g) }\end{array}$ & $\begin{array}{c}\text { Coliformes } \\
\text { Totais (NMP/g) }\end{array}$ & $\begin{array}{c}\text { Coliformes } \\
\text { Fecais NMP/g) }\end{array}$ \\
\hline I & carne in natura & $>5 \times 10^{4^{*}}$ & $6 \times 10^{3}$ & $7,5 \times 10^{3}$ & 30 & 30 \\
\hline \multirow{2}{*}{ II } & descongelada & $>8 \times 10^{4 *}$ & $6 \times 10^{3}$ & ausente & $>24000$ & 24000 \\
\hline & Maturada & $234 \times 10^{4}$ & $8 \times 10^{3}$ & ausente & 11000 & 24000 \\
\hline \multirow[t]{2}{*}{ III } & $\begin{array}{c}\text { Pós salga não } \\
\text { maturada }\end{array}$ & $2,15 \times 10^{4}$ & $7,5 \times 10^{3}$ & $6,5 \times 10^{3}$ & 200 & 200 \\
\hline & Pós salga maturada & $1 \times 10^{4}$ & $4 \times 10^{3}$ & $1,7 \times 10^{4}$ & $>24000$ & $>24000$ \\
\hline \multirow[t]{2}{*}{ IV } & $\begin{array}{l}\text { Pós secagem não } \\
\text { maturada }\end{array}$ & ausente & ausente & $5,5 \times 10^{4}$ & ausente & Ausente \\
\hline & Pós secagem maturada & ausente & ausente & $1 \times 10^{3}$ & ausente & ausente \\
\hline
\end{tabular}

* contagem bacterianas consideradas acima dos valores especificados por serem consideradas quantidades de colônias incontáveis nas placas. 


\section{RESULTADOS E DISCUSSÃO}

Os resultados obtidos nas análises microbiológicas do Jerked beef processado com carne maturada e sem maturação estão apresentados na tabela 1 .

Segundo Oliveira et al. (2008) a ausência de padrões microbiológicos na produção e comercialização da carne pode gerar negligência dos setores responsáveis pelo controle de qualidade desses produtos. Especificamente para o Jerked beef e suas fases de processamento, não existem padrões microbiológicos claros na legislação brasileira, assim, foram utilizados como parâmetro as especificações para carnes resfriadas ou congeladas in natura, carnes embaladas à vácuo - maturadas, produtos cárneos maturados (charque, Jerked beef e similares) e produtos cárneos salgados. Segundo a RDC n²12, estão especificados ç os padrões para Staphylococcus $\boldsymbol{s p p}$, coliformes totais e coliformes termotolerantes. Quanto à contagem de bactérias aeróbias mesófilas, bolores e leveduras, considerou-se dados obtidos de outras pesquisas.

A legislação brasileira não especifica um limite para a contagem total de microrganismos mesófilos. De acordo com algumas bibliografias, as contagens acima de 5 e $6 \mathrm{Log} \mathrm{UFC} / \mathrm{g}\left(1 \times 10^{4}\right.$ a $1 \times 10^{5}$ $\mathrm{UFC} / \mathrm{g}$ ) são consideradas impróprias para o consumo humano (COSTA; SILVA, 2001). Delazari (1979) relata que carnes cruas contendo concentrações de bactérias mesófilas em torno de $10^{7} \mathrm{UFC} / \mathrm{g}$ já apresentam comprometimento da qualidade. Neste estudo (POSTURA PROIBIDA) foram encontradas quantidades de bactérias aeróbias mesófilas acima de $5 \times 10^{4} \mathrm{UFC} / \mathrm{g}$ na carne in natura e acima de $8 \times 10^{4} \mathrm{UFC} / \mathrm{g}$ nas carnes descongeladas. Campos et al. (1999) encontraram contagens em média de $4,1 \times 10^{4}$ UFC onde obteve $88,2 \%$ das amostras analisadas com valores acima de $10^{2} \mathrm{UFC} / \mathrm{g}$. Oliveira et al. (2002) encontrou resultados variando de $3 \mathrm{x}$ $10^{2}$ a $7,9 \times 10^{5} \mathrm{UFC} / \mathrm{g}$ de contagens de mesófilos em carne in natura. A microbiota inicial da carne é profundamente afetada pelas condições pré e pós-abate, mesmo com a aplicação de boas práticas de produção e condições higiênico-sanitárias satisfatórias, no entanto, o crescimento destas bactérias, potencialmente patogênicas pode ser diminuído ou inibido por condições de estocagem como resfriamento, maturação e salga.
No processamento do Jerked beef após a salga na carne não maturada o resultado encontrado de bactérias aeróbias mesófilas foi de $2,15 \times 10^{4}$ $\mathrm{UFC} / \mathrm{g}$ e na carne maturada foi de $1 \times 10^{4} \mathrm{UFC} / \mathrm{g}$, no entanto, após a secagem houve ausência total de crescimento destes microrganismos. Segundo (FUNG et al., 1980) contagens bacterianas em carne de sol inferiores a $2 \log \mathrm{UFC} / \mathrm{cm}^{2}\left(1 \times 10^{1} \mathrm{UFC} / \mathrm{g}\right)$, indicam baixa contaminação, contagens entre 3 e 4 $\log \mathrm{UFC} / \mathrm{cm}^{2}\left(1 \times 10^{2}\right.$ e $\left.1 \times 10^{3} \mathrm{UFC} / \mathrm{g}\right)$ revelam contaminação intermediária e entre 5 e $6 \log \mathrm{UFC} / \mathrm{cm}^{2}$ $\left(1 \times 10^{4}\right.$ e $\left.1 \times 10^{5} \mathrm{UFC} / \mathrm{g}\right)$ representam alta contaminação, de acordo com esta definição a carne analisada apresentou alta contaminação microbiológica. $\mathrm{O} \mathrm{NaCl}$ vem sendo utilizado em salmouras para conservação de carnes, considerado um agente antimicrobiano (HAJMMER et al., 2006). A elevada concentração salina e os valores intermediários de atividade de água são importantes obstáculos encontrados no processamento do Jerked beef, sendo efetivos para a diminuição da contagem de bactérias aeróbias mesófilas, associadas à grande manipulação do alimento e que podem ser potencialmente patogênicas.

A RDC $n^{\circ} 12$ impõe o limite máximo de $10^{3}$ UFC/g para a presença de Sthaphylococccus spp para amostras de charque e similares e $3 \times 10^{3} \mathrm{UFC} / \mathrm{g}$ para carnes maturadas. Neste trabalho a contagem para estafilococos na carne in natura foi de $6 \times 10^{3}$ $\mathrm{UFC} / \mathrm{g}$ e na carne maturada de $8 \times 10^{3} \mathrm{UFC} / \mathrm{g}$, resultado maior que o encontrado por (OLIVEIRA et al., 2008) que em sua pesquisa detectou em todas as amostras de carne in natura resultados menores que $10^{2} \mathrm{UFC} / \mathrm{g}$. A contagem após a salga na carne não maturada e maturada foram respectivamente $7,5 \times 10^{3}$ e $4 \times 10^{3} \mathrm{UFC} / \mathrm{g}$, mas ao final do processamento do Jerked Beef esses microrganismos não foram mais encontrados. Esses resultados foram parecidos com os encontrados por (LARA et al., 2003), que demonstraram que o estafilococo foi incapaz de sobreviver após salga e secagem. Como descrito por (SHIMOKOMAKI et al., 1998), após a salga foi encontrado um resultado de $8,5 \times 10^{4} \mathrm{UFC} / \mathrm{g}$ e após a secagem $10^{2} \mathrm{UFC} / \mathrm{g}$. No entanto no trabalho de (COSTA E SILVA, 1999), a contagem total de bactérias mesófilas e estafilococcus não variou conforme a concentração de cloreto de sódio. 
Em função da presença de Staphylococcus aureus, Salmonella spp e Escherichia coli, produtos cárneos podem constituir um sério problema para a saúde pública, uma vez que estas bactérias são causas comuns de toxinfecções alimentares (MARQUES et al., 2006). No Estado do Paraná o Staphylococcus spp é considerado o segundo mais comum entre os patógenos causadores de surtos de intoxicação alimentares, perdendo apenas para Salmonella spp. A alta concentração do sal e baixos valores de atividade de água, são obstáculos importantes para inibir o desenvolvimento de estafilococos (LARA et al., 1999).

A legislação brasileira não especifica um limite para contagens de bolores e leveduras em carnes e derivados. Mas analisando a microbiota inicial da carne bovina (SILVA, 1995) obteve contagens na ordem de 1,66Log UFC/g (4,5 x $\left.10^{1} \mathrm{UFC} / \mathrm{g}\right)$. O Código Sanitário do Estado de São Paulo também estabelece padrões para bolores e leveduras em carnes frescas, compreendendo no máximo $10^{3}$ UFC/g. Confrontado com os resultados encontrados neste trabalho que apresentaram valores de $7,5 \times 10^{3}$ $\mathrm{UFC} / \mathrm{g}$, as carnes foram consideradas impróprias para consumo, mas após a salga e a secagem, esse número diminuiu para $1 \times 10^{3} \mathrm{UFC} / \mathrm{g}$. No trabalho de (OLIVEIRA et al., 2008) esses microrganismos foram encontrados em uma média de $2,5 \times 10^{3} \mathrm{UFC} / \mathrm{g}$. Durante o processamento da carne-de-sol é comum a utilização de utensílios de madeira que absorvem umidade e matéria orgânica, transformando-se em ambientes ideais para a proliferação dos bolores e leveduras (COSTA; SILVA, 2001).

Em relação aos Coliformes, as análises iniciais mostraram contagens significativas de 30 $\mathrm{NMP} / \mathrm{g}$ tanto para coliformes totais quanto para os coliformes termotolerantes também chamados de fecais. Ao decorrer do processamento esse número aumentou para $24000 \mathrm{NMP} / \mathrm{g}$, diminuindo ao longo do processamento e desaparecendo por completo após a salga e a secagem. $\mathrm{A} \mathrm{RDC} \mathrm{n}^{\circ} 12$ dispõe como resultado aceitável até $5 \times 10^{3} \mathrm{UFC} / \mathrm{g}$ para carne in natura e carnes maturadas e de $10^{3} \mathrm{UFC} / \mathrm{g}$ para Jerked beef e similares. De acordo com Costa e Silva (2001), a presença de coliformes totais e fecais mesmo em pequenas quantidades, não é tolerada. Oliveira et al. (2008) relatou, que os padrões portugueses permitem a presença de coliformes totais em números inferiores a $10^{2} \mathrm{NMP} / \mathrm{g}$ de carne, as amostras estavam impróprias para o consumo humano, com contagens variando de $<3$ a $2,4 \times 10^{3}$, valores parecidos com os encontrados neste trabalho. O Código Sanitário do Estado de São Paulo estabelece valores para coliformes fecais de no máximo $3,0 \times 10^{2} \mathrm{NMP} / \mathrm{g}$. Os coliformes são menos tolerantes ao $\mathrm{NaCl}$ em comparação com o Staphylococcus aureus (HAJMMER at al., 2006).

\section{CONCLUSÃO}

Os resultados apresentados nesta pesquisa comprovam que houve contaminação durante processamento do Jerked beef, mas a adição de $\mathrm{NaCl}$ e dos conservantes $\mathrm{NaNO}_{2}$ e $\mathrm{NaNO}_{3}$ assim como a maneira como foi processado reduziu significativamente esta contaminação inicial, permanecendo apenas bolores e leveduras em quantidades aceitáveis pela legislação. Se faz necessária uma boa orientação aos manipuladores de alimentos sobre os cuidados higiênico-sanitários para minimizar a contaminação e riscos de toxinfecção alimentar. Outra necessidade é a padronização dos valores aceitáveis para microrganismos no processamento do Jerked beef, para que se possa oferecer um produto seguro e de qualidade para o consumidor.

\section{REFERÊNCIAS}

ANVISA - Agência Nacional de Vigilância Sanitária. RDC $\mathrm{n}^{\circ} 12$, de 02 de janeiro de 2001 .

BORCH, E., NESBAKKEN, T., CHRISTENSEN, H. Hazard identification in swine slaughter with respect to food borne bacteria. International Journal of Food Microbiology, Amsterdam, v. 30, n. 1/2, p. 9-25, 1996.

CAMPOS, M. R. H. et al. Estudo das condições microbiológicas no fluxograma de preparação de carne bovina do cardápio de um serviço de alimentação, na cidade de Goiânia-GO. Hig. Alim., São Paulo, v.13, p. 66-67, 1999.

COSTA, E. L.; SILVA, J. A. Avaliação Microbiológica da Carne de Sol elaborada com baixos teores de cloreto de sódio. Ciênc. Tecnol. Aliment., Campinas, v.21, n.2, p.149-153, 2001.

.; ___ Qualidade da carne de sol comercializada em açougues e supermercado de João Pessoa - PB. B.CEPPA, Curitiba, v. 17, n. 2, p.137-144, 1999. 
DELAZARI, I. Microbiologia de carnes: microrganismos causadores de deterioração da carne e produtos cárneos. B. SBCTA, v. 49, p.3-39, 1979.

FAYRDIN, A. Modernidade e tecnologia chegam à industria de charque. Rev. Nac. Carne, ano 16, n.144, p.3-4, 1991.

FUNG, D. Y. C.; KASTNER, C. L.; HUNT, M. C.; DIKEMAN, M. E.; KROPF, D. Mesophilic and psychrotrophic bacteria population on hot-boned and conventionally processed beef. J. Food Prot., v.43, n.7, p.547-550, 1980.

HAJMEER, M.; CEYLAN, E.; MARSDEN, J. L.; FUNG, D.Y.C. Impact of sodium chloride on Escherichia coli O157:H7 and Staphylococcus aureus analysed using transmission electron microscopy. Food Microbiology, v.23, p.446-452, 2006.

LARA, J. A. F.; SENIGALIA, S. W. B.; OLIVEIRA, T. C. R. M.; DUTRA, I. S.; PINTO, M. F.; SHIMOKOMAKI, M. Evaluation of survival of Staphylococcus aureus and Clostridium botulinum in charqui meats. Meat Science, v.65, p.609-613, 2003.

LARA, J. A. F.; PINTO, M. F.; DUTRA, I. S.; SHIMOKOMAKI, M. Botulismo, Risco decorrentes do processamento inadequado os alimentos. $\mathrm{O}$ charque como enfoque. Higiene Alimentar, v.13, p.56-62, 1999.

MARQUES, S. C.; BOARI, C. A.; BROKO, C. C.; NASCIMENTO, A. R.; PICCOLI, R.H. Avaliação higiênico-sanitária de linguiças tipo frescal comercializadas nos municípios de Três Corações e Lavras - MG. Ciênc. agrotec., v.30, n.6, 2006.

OLIVEIRA, S.; SILVA, J. A.; MACIEL, J. F.; AQUINO, J. S. Avaliação das condições Higiênico-sanitárias de carne bovina comercializada em supermercados de João Pessoa. Alim. Nutr., v.19, n.1, p.61-66, 2008.

OLIVEIRA, N. M. S.; NASCIMENTO, L. C.; FIORINI, J. E. Isolamento e identificação de bactérias facultativas mesófilas em carnes frescas bovinas e suínas. Hig. Alim., São Paulo, v.16, n. 94, p.68-74, 2002.

PARDI, C. M.; SANTOS, L. F.; SOUZA, E. R.; PARDI, H. S. Ciência, higiene e tecnologia da carne. Goiânia: Editora UFG, 1995. p.586.

PENNA, R.; SCHETTINI, M. Como produzir carne maturada. Viçosa: Centro Produções Técnicas, 1999.

PINTO, M. F., PONSANO, E. H. G.; FRANCO, B. D. G. M.; SHIMOKOMAKI, M. Controle de Staphylococcus aureus em charques (Jerked beef) por culturas iniciadoras. Ciência e Tecnologia de Alimentos, Campinas, v.18, n.2, 1998. (Não tem a página)

PUGA, D. M. U.; CONTRERAS, C. J. C.; TURNBULL, M. R. Avaliação do amaciamento de carne bovina de dianteiro (Triceps brachii) pelos métodos de maturação, estimulação elétrica, injeção de àcidos e tenderização mecânica. Ciência e Tecnologia de Alimentos, v.19, n.1, p. 1-10, 1999.

SABADINI, E., HUBINGER, M. D., SOBRAL, P. J. do A., CARVALHO Jr, B. C. Change of water activity and meat colour in the elaboration process of dehydrated salted meat. Ciência Tecnologia de Alimentos, v. 21, n.1, 2001.

SÃO PAULO (Estado) Secretaria da Saúde. Código Sanitário. Decreto $\mathrm{n}^{\circ} 12.342$ de 27 de setembro de 1978: regulamento da promoção da saúde no campo da competência da Secretaria do Estado da Saúde, São Paulo, 5. ed. p.60, 1992.

SHIMOKOMAKI, M.; YOUSSEF, E. Y.;TERRA, N. N. Curing. Encyclopédia of Food Sciences and Nutrition, 2.ed. St Louis, 2003. p. 1702-1707.

.; FRANCO, B. D. G. M., CARVALHO Jr., B. C. Charque e produtos afins: tecnologia e conservação - uma revisão. Bol. Soc. Bras., Ciênc. Tecnol. Aliment., v.21, n.1, p.25-35, 1987.

SILVA, J. A. Microbiologia da carcaça bovina: uma revisão. Revista Nacional da Carne, v.24, n. 10, p. 62-87, 1997.

Extensão da vida-de-prateleira da carne bovina pela utilização de sanitizantes físicos e químicos. Campinas, 1995. 119 p. Faculdade de Engenharia de Alimentos, Universidade Estadual de Campinas (UNICAMP).

Tópicos da tecnologia de alimentos. São Paulo; Livraria Varela, 2000. 227p.

SILVA, M. C. Avaliação da qualidade microbiológica de alimentos com a utilização de metodologias convencionais e do sistema SimPlate. Piracicaba, 2002. 75f. Dissertação (Mestrado em Ciência e Tecnologia de Alimentos) - Escola Superior de Agricultura Luiz de Queiroz.

SILVA, M. C. D. Incidência de Staphylococcus aureus enterotoxigênicos e coliformes fecais em carne de sol comercializada na cidade do Recife- PE. Recife, 1991, 77 p. Departamento de Nutrição, Universidade Federal de Pernambuco (UFPE).

TAVARES, T. M., SERAFINI, A. B. Avaliação Microbiológicas de Hambúrgueres de Carne Bovina Comercializadas em sanduicheiras tipo Trailers em Goiânia (GO). Revista de Patologia Tropical, v. 32, p.45-52, 2003.

VANDERZANT, C.; SPLITTSTOESSER, D. F. Compendium of methods for the microbiological examination of foods, 3.ed. Washington: APHA, 1992. p. 1219.

VASCONCELOS E. C; ZAPATA J. F. F.; FIGUEIREDO E. A.; BRANCO M. A. A. C.; BORGES A. S. A microbiota da carcaça e da carne ovina tratada com ácido acético, embalada a vácuo e maturada por 48 dias. Ciência e Tecnologia de Alimentos, Campinas, v.22, n.3, 2002. 